\title{
Hepato Splenic Tuberculosis in Acute Cholecystitis
}

\author{
Mountassir Moujahid ${ }^{*}$, Hicham Iraqui', Mohamed Ghari², Issam Serghini ${ }^{3}$, \\ Khalid Chekoura ${ }^{3}$, Moulay Hassan Tahiri ${ }^{1}$ \\ ${ }^{1}$ Departement of Surgery, 5th Military Hospital, Guelmim, Morroco \\ ${ }^{2}$ Departement of Radiology, 5th Military Hospital, Guelmim, Morroco \\ ${ }^{3}$ Departement of Reanimation, 5th Military Hospital, Guelmim, Morroco \\ Email: ${ }^{\text {m.moujahid@gmx.fr }}$
}

Received 16 June 2014; revised 1 July 2014; accepted 18 July 2014

Copyright (C) 2014 by authors and Scientific Research Publishing Inc.

This work is licensed under the Creative Commons Attribution International License (CC BY).

http://creativecommons.org/licenses/by/4.0/

(c) (i) Open Access

\begin{abstract}
Background: The tuberculosis is an endemic disease in our country; it remains a major public health problem. Liver and splenic tuberculosis is a classic disease which represents $1.5 \%$ of all gastrointestinal tuberculosis. Patients and Methods: We reported the case of a fifty-six years old patient admitted in the department of surgery for acute cholecystitis, and the biological balance showed a hyperleukocytosis at 16,000 elements $/ \mathrm{mm}^{3}$ and a CRP at 25 with a light cholestasis. The abdominal scanner showed a micronodular splenomegaly with coelio mesenteric ganglions. We discovered a tuberculosis location in the liver and the spleen and we realized a cholecystectomy with a hepatic biopsy and a splenectomy. Results: A gallbladder ablation associated with an enlarged spleen and liver biopsy was diagnosed with liver and splenic tuberculosis. The patient was put under anti tubercular treatment with the good clinical and radiological evolution. Conclusion: The diagnosis of tuberculosis should always be considered especially in endemic countries.
\end{abstract}

\section{Keywords}

Tuberculosis, Endemic, Liver, Spleen, Diagnosis, Treatment

\section{Introduction}

Tuberculosis remains a frequent and mortal disease in the world; in nine million new cases, the annual number of deaths due to the tuberculosis is 3 million [1]. It remains a major problem of public health. In Morocco, during the year 2007, 500 at 1000 deaths are owed to tuberculosis, and 25.5 new cases were listed, what corres-

"Corresponding author.

How to cite this paper: Moujahid, M., Iraqui, H., Ghari, M., Serghini, I., Chekoura, K. and Tahiri, M.H. (2014) Hepato Splenic Tuberculosis in Acute Cholecystitis. International Journal of Clinical Medicine, 5, 871-874. 
ponds to a rate of incidence of 87 new cases for 100,000 inhabitants. It is a disease which can affect any organ. The hepatic and splenic tuberculosis is a classic localization which represents $1.5 \%$ of all the digestive tuberculosis [2]. We reported hepatic and spleen localization discovered during a surgical cure of an acute cholecystitis.

\section{Observation}

Fifty-six years old men, without surgical medical histories admitted by emergencies for the coverage of an acute cholecystitis. The clinical examination showed a pain of the right hypochondria with a positive Murphy sign, and a splenomegaly evolving in a feverish context $38.5^{\circ} \mathrm{C}$. In the biological balance a hyperleukocytosis at 16,000 elements $/ \mathrm{mm}^{3}$ and a CRP at 25 with and a light cholestasis. The PCR is not the usual practice in our institution. The abdominal echograph showed a lithiasis vesicle with a splenomegaly. The abdominal scanner showed a micronodular splenomegaly with coelio mesenteric ganglions (Figure 1). The patient was operated by a median way, the abdominal exploration showed a dysmorphic liver and a lithiasic vesicle in thickened wall and an enormous micronodular splenomegaly with coelio mesenteric ganglions. We realized a cholecystectomy with a hepatic biopsy and a splenectomy (Figure 2). The follow up were simple and the patient received an antipneumococcic and hemophilus influensae vaccination. The anatomo pathologic report was in favour of a hepatic and spleen localization of the tuberculosis. The patient was confided to the service of medicine for taken care, the research for BK in spits and urines was negative as well as the intradermic reaction of tuberculin. An antitubercular treatment with Streptomycin, Rifampicine, Isoniazide and Pyrazinamide during four months followed by an association with Rifampicine and Isoniazide during two months with a good biological and radiological clinical evolution on a backward movement of four year.

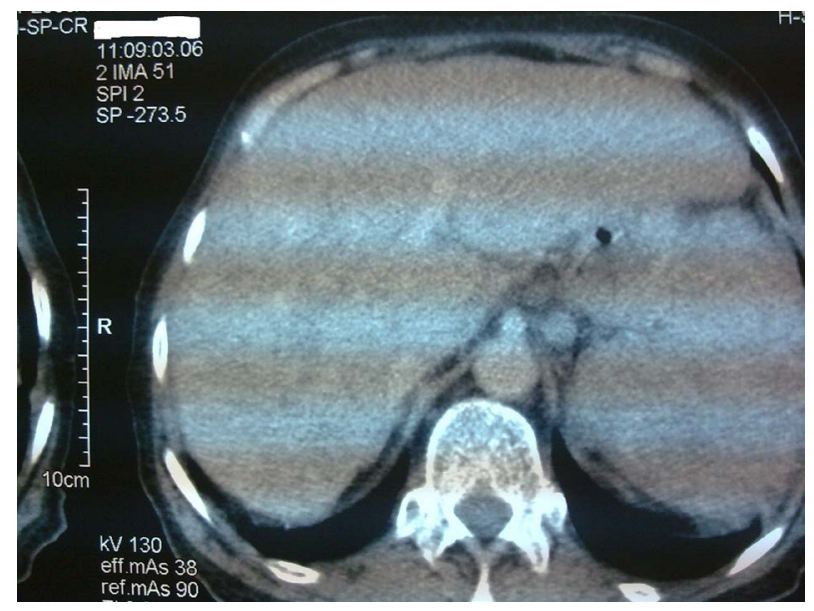

Figure 1. Abdominal scanner showing micro nodular hurts of the spleen.

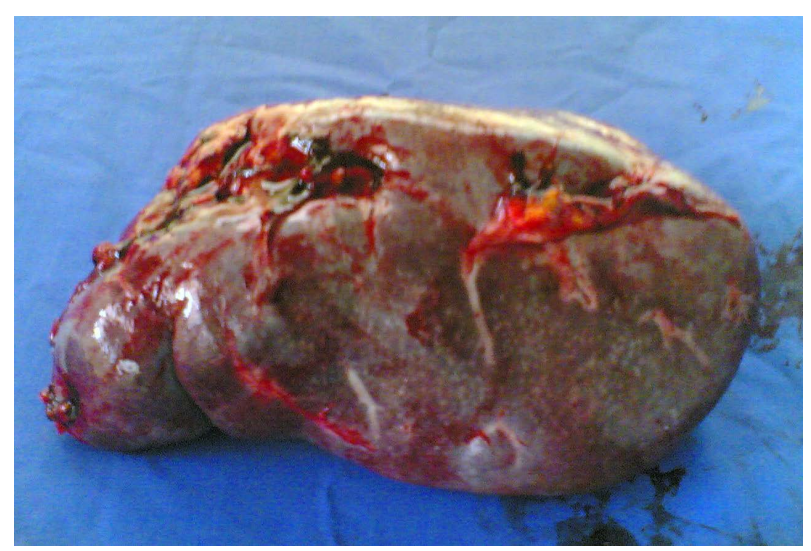

Figure 2. Splenectomy piece. 


\section{Discussion}

Tuberculosis is a disease of the young adult: $70 \%$ of the sick are from 15 to 45 years old [3]. The human infection is, by air traffic; most of the time from droplets of saliva, or by a hematogenic distribution. The other ways of mucous, digestive, cutaneous infection are possible but rare [2]. The most frequent achievement of the digestive tract is represented by the ileocoecal region because it is plentiful cloth lymphoid and also represents a zone of relative stase [4]. The contamination of the spleen and the liver is made by blood and/or lymphatic way from a foyer of firstly infection, generally ganglionic, thoracic, more rarely abdominal [2]. The peritoneal localizations of the tuberculosis are rare but classic [1]. The hepatosplenic infringement during the tuberculosis is classic but very rarely revealing the disease representing approximately $1.5 \%$ of all the digestive tuberculosis [2]. It can be met during the presence of a visceral multi-tubercular miliary or at immunosuppressed patients [5]. The clinical symptoms are variable what can be sometimes a source of delay diagnostic. In the primitive, very rare shape, it realizes often misleading aspects, difficult diagnosis. Clinically translated by an almost constant feverish syndrome, a change of the general state, a hepatomegaly and/or a splenomegaly. On the biological plan, there is frequently an inflammatory syndrom. The intra dermo reaction in the tuberculin is neither sensitive, nor specific. The hepatic balance is sometimes perturbed. In our case the clinical examination showed a splenomegaly with a hepatomegaly evolving in a feverish context in $38.5^{\circ} \mathrm{C}$ and a sign of positive Murphy in touch with the acute cholecystitis. The biological balance showed a hyperleukocytosis at 16,000 elements/mm ${ }^{3}$, a CRP at 25 and a light cholestasis. The medical imaging allows evoking the diagnosis of tuberculosis the lung radiography is of a big interest when it shows pleura pulmonary tuberculosis evolutionary lungwort or aftereffect. The radiography without preparation can show calcifications intra spleen or mesenteric ganglion. The hepatosplenic achievement can dress several aspects: micronodular, macronodular or abscessed. The micro nodular shape is the most frequent, being translated in the echograph by an accentuation of the echogenicity or by micronodular hypoechogenic aspect. The macro nodular shape called tuberculoma is rare. It realizes one or several masses of variable echo structure most of the time hypoechogenic without posterior strengthening, sometimes containing calcifications [6] [7]. In scanning, the aspect depends on the evolutionary stage of the disease. The hurts of the beginning are iso dense. They become hypo dense by caseous necrosis then eventually calcify at the aftereffect stage [2] [6]. The injection of contrast pulls an annular raising. In the magnetic resonance imaging the most suggestive aspect is the hyper intense lesion in periphery, a lesser Intensity in the center on balanced sequences T2, and who raises in periphery after injection of contrast [8]. The diagnosis of the hepatic and spleen tuberculosis remains difficult in the absence of other accessible tubercular foyer, especially as other pathologies can present the same clinical and radiological aspect as the sarcoidosis, the lymphoma and the metastasis [7]. This brings us to discuss the utility of a draining guided by echograph or scanner allowing to avoid to the patients in already altered general state, a heavy surgical gesture and of possible post operative complications [5] [7]. It is at the same time a diagnostic and therapeutic gesture [9]. The treatment of the hepatic and spleen tuberculosis is usually medical basing on anti tuberculosis drugs (Streptomycin, Rifampicine, Isoniazide, Pyrazinamide) during two months and Rifampicine, Isoniazide during four months. Certain authors recommend until 9 months of treatment even one year [3] [8] [10]. The evolution is favorable in the majority of the cases (90\%) with disappearance of the symptoms and the normalization of the radiological images at the end of treatment [7] [10]. The recourse to the surgery is made in therapeutic aim, to eradicate a septic foyer resisting to the medical treatment or in case of complication, and the diagnostic aim when the percutaneous draining is dissuaded (disorder of the haemostasis) or not decisive or technically impracticable [5] [9] [10]. In our case, the diagnosis was realized during a cholecystectomy in the anatomopathologic study of the splenectomy and the hepatic biopsy.

\section{Conclusion}

The hepatic and spleen tuberculosis represents approximately $1.5 \%$ of all the digestive tuberculosis. Its diagnosis must be always evoked especially in the countries of tubercular endemic disease. The treatment, especially medical treatment, is based on anti tuberculosis drugs.

\section{References}

[1] Ottmani (1996) Situation actuelle de la tuberculose au Maroc. Guide de la lutte antituberculeuse Santé en chiffre.

[2] Valencia, M.E., Moreno, V., Soriano, V., et al. (1996) Tuberculous Hepatosplenic Abscess, Human Immunodeficiency 
Virus Infection and Multiresistant Tuberculosis. Revista Clinica Espanola, 196, 816-820.

[3] Choi, B.I., Im, J.G., Han, M.C., et al. (1989) Hepatosplenic Tuberculosis with Hypersplenism: CT Evaluation. Gastrointestinal Radiology, 14, 265-267. http://dx.doi.org/10.1007/BF01889212

[4] Arslan, A., Ciftçi, E., Ceylan, N., et al. (1998) Abdominal Tuberculosis. A Case Report. Acta Radiologica, 39, 693694. http://dx.doi.org/10.3109/02841859809175499

[5] Adnani, A. and Dafiri, R. (2005) Hepatosplenic Tuberculosis in Children. Journal of Radiology, 86, 1710-1711.

[6] Buxi, T.B., Vohra, R.B., Sujatha, Y., et al. (1992) CT Appearances in Macronodular Hepatosplenic Tuberculosis: A Review with Five Additional New Cases. Computerized Medical Imaging and Graphics, 16, 381-387. http://dx.doi.org/10.1016/0895-6111(92)90056-F

[7] Cheng, A.C. and Johnson, D.F. (2006) Multiloculated Hepatosplenic Abscesses. Clinical Infectious Diseases, 43, 264265. http://dx.doi.org/10.1086/505308

[8] Kansal, A.P., Chopra, V., Singh, H., et al. (2008) Tubercular Hepatic Abscess-A Rare Presentation. Indian Journal of Tuberculosis, 55, 217-220.

[9] Kumar, V. and Pandey, D. (2008) Isolated Hepatosplenic Tuberculosis. Hepatobiliary \& Pancreatic Diseases International, 7, 328-300.

[10] Mahi, M., Chaouir, S., Amil, T., et al. (2002) A Case of Isolated Tuberculosis Spleen. Journal of Radiology, 83, 479474. 
Scientific Research Publishing (SCIRP) is one of the largest Open Access journal publishers. It is currently publishing more than 200 open access, online, peer-reviewed journals covering a wide range of academic disciplines. SCIRP serves the worldwide academic communities and contributes to the progress and application of science with its publication.

Other selected journals from SCIRP are listed as below. Submit your manuscript to us via either submit@scirp.org or Online Submission Portal.
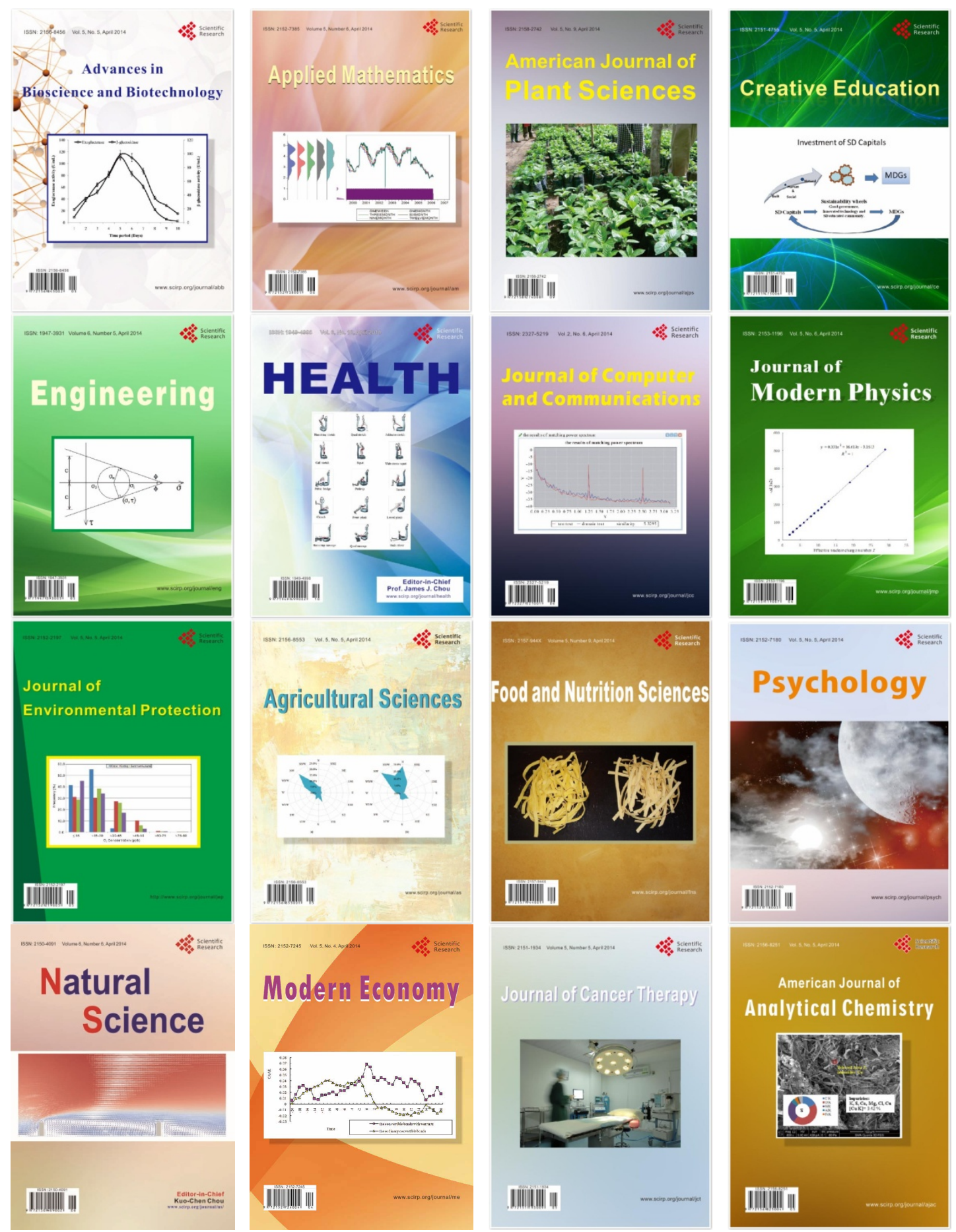